\title{
Uma aventura marítima no Livro de Linhagens do Conde D. Pedro*
}

\section{A Maritime Adventure in Count D. Pedro's Lineage Book}

\author{
JOSÉ CARLOS RIBEIRO MIRANDA \\ Universidade do Porto - SMELPS/IF/FCT \\ mirandajor@gmail.com
}

\section{Palavras-chave}

Gascos; Navarra; vikings; condes portucalenses; Riba Douro; Baião; Araldes.
O Livro de Linhagens do Conde Dom Pedro é conhecido pelas narrativas épico-lendárias que em muito têm contribuído para a sua difusão na actualidade. Entre essas narrativas sobressai a que diz respeito à invasão do rio Douro por uma armada de gascos que, após dura luta contra os mouros que dominavam a região, se instalaram em Baião, dando origem a uma das mais importantes linhagens fundadoras do reino de Portugal. Mas essa narrativa pode não ser mais do que a face visível de uma invasão em grande escala do território portucalense que se deu entre 1014 e 1016, envolvendo vikings e gentes de outras proveniências, tendo marcado sensivelmente o futuro do que viria a ser, um século depois, o reino de Portugal.

Count Dom Pedro's Livro de Linhagens is well-known for its epiclegendary narratives that have contributed very much to its diffusion nowadays. Among these narratives stands out the one related to the invasion of the Douro River by an armada of Gascons which, after a hard fight against the Moors that dominated the region, settled in Baião, and became one of the most important founding lineages of the kingdom of Portugal. But this narrative may be no more than the visible face of a largescale invasion of the Portuguese territory that took place between 1014 and 1016, involving Vikings and other people with different origins, which marked the future of what would become, a century later, the kingdom of Portugal.

\footnotetext{
* Este trabalho foi elaborado no âmbito do projecto MELE (Da Memória Escrita à Leitura do Espaço, POCI-01-0145-FEDER-032673), co-financiado pelo Programa Operacional Competitividade e Internacionalização (POCI) através do Portugal 2020 e do Fundo Europeu de Desenvolvimento Regional (FEDER), e por fundos nacionais através da FCT-Fundação para a Ciência e a Tecnologia.
} 


\section{JOSÉ CARLOS RIBEIRO MIRANDA}

$\mathrm{O}$ presente volume pretende ser uma homenagem às empresas marítimas portuguesas, tomando como grande ponto de referência a viagem de Fernão de Magalhães à volta do globo terrestre, terminada por Sebastián Elcano em 1522. Iniciativa marcante a nível mundial, como o foi certamente, induz por vezes a ideia de ter sido um ponto de partida com pouco que o antecedesse, a não ser, obviamente, as sucessivas campanhas que desde as costas de África levaram os navegadores portugueses, e seus acompanhantes de várias origens, sucessivamente, ao cabo Bojador, à Índia, ao Brasil e à América. Mas como quase sempre sucede numa História cujo pendor é essencialmente comemorativo e voltado para o panegírico, tal assunção deixa na obscuridade outras empresas náuticas que tiveram lugar em momentos anteriores, onde certamente os portugueses não tiveram o mesmo protagonismo, embora nelas estivessem inegavelmente implicados.

Não pretendendo ir muito longe nesse elenco, gostávamos de chamar a atenção para o Norte, donde durante várias centenas de anos vieram navegadores normandos visitar a Península Ibérica, na maioria dos casos com objectivos predatórios bem confirmados, mas noutros, com intenções diferentes, entre as quais figura o propósito colonizador. Tudo isso entre nós tem merecido pouco mais do que notas de pé de página, embora, em alguns casos, os eventos envolvidos sejam importantes até pela possível sequência histórica ou literária que vieram a ter ${ }^{1}$.

Nesse sentido, chamaremos a atenção para uma interessante prosa que surge no mais prestigiado dos nobiliários portugueses da Idade Média - o Livro de Linhagens do Conde D. Pedro - onde é possível ler o desfecho de uma campanha marítima que teria tido lugar no século XI, ou seja, numa altura prévia à configuração do Portugal "histórico", protagonizada não por normandos ou vikings - na altura, designados por lordemanos - mas sim por "gascos", à frente dos quais avultaria a figura de Monio, lo Gasco. Vejamos o texto:

Este dom Moninho Veegas, o Gasco, primeiro, veo a Portugal em tempo d'el rei dom Ramiro de Leom, e veo de Gasconha, e outro seu irmão com el, que foi bispo do Porto, e havia nome dom Sesnando. Este morreo, e jaz em Vila Boa do Bispo. E veo com ele o bispo dom Nonego, que jaz no moesteiro de Coyaos, e veerom com ele dous seus filhos: ũu houve nome dom Egas Moniz, o Gasco, e o outro houve nome dom Garcia Moniz, o Gas[c]o. E veerom com ele muitos e boos cavaleiros e muitos e boos escudeiros filhos d'algo. E veerom por mar portar na foz de Doiro, que é antre o Porto e Gaia, e em aquel tempo chamavom-lhe a foz Doiro Mao. E lidarom i com mui gram peça de Mouros per muitas vezes, e matarom i ũu dos filhos, que havia nome dom Garcia Moniz, o Gasco. E aacima, venceo os Mouros, e veo gaanhando deles a terra per Riba de Doiro acima, de ũa parte e da outra. (Mattoso, 1980: 36A1)

$\mathrm{Na}$ realidade, a primeira ocorrência desta lenda revestidora, como se verá, de uma dada realidade histórica, não vê a luz primitiva com o relato de Dom Pedro de Barcelos, mas um pouco antes, no Livro Velho de Linhagens, o mais antigo escrito genealógico confeccionado em terras portuguesas, por volta de 1270. Aí, porém, as personagens envolvidas não são tantas, nem a respectiva denominação é tão abundante. A mais relevante - Monio lo Gasco, com aquele artigo sem queda do "l" que confirma a sua procedência de terras orientais da Península

\footnotetext{
${ }^{1}$ Uma síntese recente sobre a história marítima portuguesa na Idade Média pode ler-se em Duarte (2003).
} 
ou mesmo francesas - não tem nenhum patronímico, muito menos "Viegas", atribuição retrospectiva específica do Livro do Conde que não é confirmada por nenhuma fonte documental coeva. Vejamos o curto excerto do Prólogo deste livro onde a equivalente prosa tem lugar:

a $5^{a}$ geração que veio postrimeira a Portugal de Gasconha, Dom Monio Lo Gasco, donde vem os que ora chamam de Riba de Douro, e veio com ele seu irmão o Bispo Dom Sesnando, que jas em Vila Boa do Bispo, e o Bispo Dom Enego, seu irmão que jaz em Tuyas ${ }^{2}$.

Como se verifica, Dom Monio (Munio, Nuno e não "Moninho") era proveniente da Gasconha, e não duvidamos de que as listas genealógicas a que o Conde de Barcelos teve acesso lhe permitissem admitir que tivera dois filhos. Aliás, já o Livro Velho dizia que filhas deste prócer haviam "consogrado" com membros de outras linhagens, nomeadamente a da Maia.

De resto, se exceptuarmos aquele patronímico "Veegas" que o Conde lhe atribui, cuja forma é específica de Portugal - sendo, por isso, improvável que pertencesse anteriormente a Dom Monio $^{3}$-, a narrativa transmitida pelo seu Livro de Linhagens, para além da tonalidade épica, possui mesmo alguma verosimilhança histórica. Homens vindos de fora, pela via marítima, com uma armada tão numerosa que permitisse defrontar os mouros que dominavam desde a região do Porto até para lá de Lamego, não parece cenário sem credibilidade, sendo até muito provável, tendo em conta que documentos de 1014 e 1015 atestam, de facto, a presença destes gascos, sobretudo de Dom Monio, na corte condal de Guimarães, onde sobressaía a personalidade de Dona Toda, mulher do Conde portucalense Mendo Gonçalves, entretanto falecido em combate ${ }^{4}$. Na realidade, a serem aceitáveis estas informações, os ditos gascos vêm ocupar um território do Douro interior - entre os rios Sousa e Tua - que o poder condal de Guimarães havia muito não era capaz de controlar militarmente, nomeadamente após as incursões de Almansor que tiveram no vale do Douro um dos seus principais teatros de operação guerreira.

\section{Narrativa épica e realidade histórica}

Será tal narrativa apenas mais um lance épico, muito ao gosto dos livros de linhagens, particularmente do Livro de Linhagens do Conde D. Pedro, que contava já com uma versão refundida e ampliada de uma narrativa muito afim - a Lenda de Gaia? A nosso ver, há nesta prosa sobre os gascos no Douro seguramente a mão do Conde, com a sua apetência por enredos guerreiros de partilha do poder entre cristãos e mouros. Mas a alusão a "em Doiro antr'o Porto e Gaia", mais do que remontar a essa "Lenda", cita literalmente o refrão de um poema de Rui Gomes de Briteiros - que o Conde compila no seu Cancioneiro - onde o trovador prenuncia o rapto de Elvira Anes ${ }^{5}$, a filha mais nova de João Peres da Maia, evento

\footnotetext{
2 Manuscrito 47-XIII-10 da Biblioteca Nacional da Ajuda, fol. 32r.

${ }^{3}$ Ainda que "Benegas", igualmente evolução de "Ibn Egas", se viesse a tornar corrente noutras partes da Península, nomeadamente na Andaluzia.

${ }^{4}$ A presença de Monio lo Gasco na corte da condessa Toda, viúva do conde Mendo Gonçalves, é atestada em documentos de 1014 e 1015 - cf. Mattoso (2001: 44).

${ }^{5}$ Sobre o tema, ver Miranda (2016).
} 


\section{JOSÉ CARLOS RIBEIRO MIRANDA}

que virá ser recordado nesse mesmo Cancioneiro e nos livros de linhagens mais tardios - o Livro do Deão e o Livro do Conde - embora não no Livro Velho ${ }^{6}$.

Não nos determos na rede de sentidos e evocações que este refrão comporta, sendo, contudo, claro que em todos os casos se está perante estórias que têm em comum a violação de uma terra por parte de alguém. A procura da mulher fecundável é sempre um correlato dessa luta pela terra, originando, em todos os casos mencionados, a fundação de uma linhagem: os da Maia, na Lenda de Gaia; os Briteiros-Maia, no caso do cantar trovadoresco; e a linhagem dos Ribadouro no caso acima transcrito.

Portanto, nada impediria que este relato fosse tão só uma manifestação do apreço de Pedro de Barcelos por este tipo de enredos, não fora a existência de alguns elementos referenciais que apontam no sentido de nem tudo se dever à imaginação do genealogista. $\mathrm{O}$ primeiro diz respeito à presença de Monio lo Gasco em território portucalense em 1014 e 1015, que atrás mencionámos. Ora, nessa época, é de todo improvável que Monio e os seus companheiros tivessem vindo implantar-se naquele território sem defrontar o poder mouro que dominava a parte sul do rio, sendo também credível que se tenham vindo a estabelecer na margem norte desse rio, de tal modo era débil, como dissemos, o poder dos condes de Guimarães poucos anos após a saída do território das tropas de Almansor e ainda após a morte do Conde Mendo Gonçalves.

Ou seja, a memória de confrontos entre os mouros fortificados em Lamego e os novos ocupantes é certamente verosímil, e não custa acreditar que tenha base histórica. Já outra questão é saber se a vinda desses "gascos" se terá realizado por via marítima, tornando historicamente aceitável uma parte substancial do relato do Conde, nomeadamente a morte de um irmão do prócer que assumia a chefia, ou se essa vinda terá ocorrido por via terrestre, o que se nos afigura notavelmente mais difícilde todas as perspectivas, nomeadamente logística e militar.

Neste ponto particular, cremos que há na narrativa do Conde elementos que levam a pensar que o autor teve realmente acesso a uma memória do confronto naval no Douro, nomeadamente na forma como é identificado o local desse confronto, que teria tido lugar na “...foz Douro Mau”. Trata-se, com toda a certeza, de um equívoco, já que a região de "Rio Mau", assim chamada pela topografia difícil adquirida na região pelo rio, pelos afluentes e relevos circundantes ${ }^{7}$, não se situa na foz do rio Douro, mas sim algumas dezenas de quilómetros a montante, onde se situavam as atalaias e fortificações do sistema defensivo mouro da cidade de Lamego ( $c f$. Ferreira, 2004). É credível que a confrontação entre embarcações gascas e sistema defensivo mouro se tenha dado aí, tendo o relato do Conde - de um modo muito conservador, mas bem característico da escrita historiográfica medieval mantido essa memória, embora transportando a acção para a Foz do Douro "antre o Porto e Gaia”, onde adquiria sentido a evocação dos episódios poético-lendários a que atrás aludimos.

Portanto, sem pretender dar como provado que uma armada de homens provenientes da Gasconha entrou no Douro e foi fixar-se em terras de Baião após vencer a resistência moura, temos essa hipótese como muito provável, até porque, como veremos adiante, há outros argumentos que a suportam, embora a base documental para o conhecimento de factos ocorridos nestas cronologias seja pouca e muito problemática.

\footnotetext{
${ }^{6}$ Aquilo que nos outros livros de linhagens e no Cancioneiro é considerado um "rousso", é referido, no Livro Velho de Linhagens, como uma inócua notícia: "[...] a sobredita dona Elvira Anes foi casada com Rui Gomes de Briteiros", Mattoso \& Piel (1980).

7 Mesmo junto à foz do Rio Mau há um ponto sintomaticamente designado "Raiva" (ravina).
} 


\section{Gasconha \& Navarra}

Em todo o caso, os ditos gascos, capazes de tal empreendimento, merecem uma mais detida abordagem. O que era o ducado da Gasconha nestes anos ao redor de 1014, pouco tempo após Almansor ter reafirmado o poder do Sul muçulmano sobre toda a Península Ibérica? $\mathrm{Na}$ realidade, o processo de formação deste domínio territorial é pouco claro, sendo consensual que a uma população basca se vem sobrepor uma aristocracia guerreira cujas ligações preferenciais se fazem com o norte de França, mas também com a Aquitânia e, inevitavelmente, com o sul ibérico onde se afirma com grande vigor o reino de Pamplona.

Para o período que nos interessa, avulta a figura do Duque Guilhem II Sans, ou Sancho, da Gasconha, que morre em 996, ao qual sucede o filho Sancho Guilhem, ou Guillén, cuja ligação preferencial à Navarra é patente, declarando mesmo algumas fontes que se tornara vassalo de Sancho III de Pamplona (cf. Collins, 1990; Lacarra, 1972), um dos mais longevos reis da época, a quem se deve um período de hegemonia política navarra sobre o território norte da Península Ibérica. Sancho Guillén apenas morre em 1032, o que significa, sem grande margem para dúvida, que uma expedição de gascos em direcção a ocidente, por volta de 1014, apenas teria condições de se realizar vitoriosamente se tivesse contado com o apoio desse duque e de Sancho III. Não surpreenderia se fosse entendida dentro dos planos políticos do rei navarro no sentido de estender a sua supremacia política a terras tradicionalmente leonesas, visto ser já soberano em Castela pelo seu casamento com a condessa Munia.

Se o contexto político da vinda dos gascos a Portugal não parece suscitar grandes dúvidas - na condição de ser assumido um ponto de vista que não limita a história portuguesa ao estrito espaço "nacional" -, já o contexto militar é mais inseguro e poderá resumir-se na tentativa de dar resposta às seguintes questões: teriam os gascos uma armada e uma tradição militar marítima tão forte que lhes permitisse levar a cabo uma empresa naval desta dimensão? E, naturalmente, qual seria a relação desta região pirenaica e dos seus habitantes com os vikings, cuja supremacia marítima nesta altura era incontestável?

Nestes pontos, contudo, as respostas são mais difíceis porque, ao que nos foi dado verificar, a investigação não se revela muito abundante. Na realidade, a questão central é a de saber em que medida as populações da Gasconha, intensamente fustigadas pelas campanhas nórdicas, mantiveram uma posição de permanente defesa e de recusa da presença dos invasores, como pretende a historiografia tradicional ( $c f$. Monlezun, 1846), ou se, pelo contrário, foram assimilando a vários níveis a cultura dos normandos, com particular relevo para a actividade marítima, seja ao nível da prática da pesca, seja ao nível militar. A tendência actual vai no sentido de admitir esta última possibilidade, embora nos deparemos mais com convicções do que realmente com investigação objectiva.

Seja como for, conhecendo o território duriense dessa época, não nos restam dúvidas de que a armada invasora do Douro teria de estar bem preparada e de ser numericamente abundante. De outro modo, não conseguiria estabelecer-se no resguardado território de Baião, de frente para as várias fortalezas muçulmanas que circundavam Lamego. Mesmo tendo permanecido na margem norte do Douro - a passagem para sul dos continuadores da iniciativa de Monio lo Gasco apenas se deu mais de cinquenta anos depois, terminadas as campanhas militares de Fernando Magno, filho do rei Navarro acima referido -, para ter sucesso, a presença desses guerreiros invasores e colonizadores terá de ter disposto de inegável força militar. Ainda que contassem com a cumplicidade política dos condes de Portucale, estes não tinham capacidade militar suficiente para lhes prestar um auxílio válido. 


\section{JOSÉ CARLOS RIBEIRO MIRANDA}

\section{A invasão viking de 1014-1016}

Nestas condições, é provável que este grupo tenha contado, directa ou indirectamente, com outros apoios. Na realidade, tendo como ponto de partida um importante documento do Arquivo Nacional da Torre do Tombo, mas proveniente do Mosteiro de Moreira da Maia ${ }^{8}$, narrando uma incursão viking no Douro ocorrida em 1015, é possível reconstruir melhor o contexto vivido na região duriense nesse limitado período de tempo que vai de 1014 a 1016. É de salientar o esforço no sentido de aprofundar esse conhecimento realizado nos últimos anos nos meios universitários, sobretudo português (cf. Pires, 2018; Barroca; Silva, 2018).

Ora, aquele documento alude à predação de bens e pessoas levada a cabo por piratas nórdicos, sendo estas últimas devolvidas mediante pagamento de resgate no ano seguinte. Isto implicou a construção de uma base de Inverno onde os normandos permaneceram durante esse período, dando tempo a que os montantes pedidos fossem reunidos, o que nem sempre se terá revelado fácil de concretizar.

[...] In Era M L iij mense Iulio ingressi fuerunt filus et neptis Lotminis multis in Doiro, predans et captivans de Doiro in Aue per viiij menses. Ibi captiuarunt tres filias de me ipso Amarelo et remansi mesquino; pasarunt Leodemanes illos catiuos a uindere totos, nominibus Serili, Ermesenda, Faquilo, et non aueua que dare pro eas a Leodemanes ${ }^{9}[\ldots]$

No caso vertente, temos um pai, de seu nome Amarelo Mestaliz, que procura resgatar as suas três filhas que haviam sido capturadas, o que apenas consegue fazer com muito custo e após algumas tentativas fracassadas. Ora isto passa-se em 1015, um ano após os gascos se terem apresentado também no Douro, não propriamente para predar, mas antes para abrir caminho até se estabelecerem nas terras de Baião à vista da cidade de Lamego, então muçulmana. De lembrar que estes (ou outros) normandos permaneceram na região até 1016, ano em que os anais portugueses declaram que atacam e destroem o castelo de Vermoim situado na margem norte do rio Ave ${ }^{10}$, o que terá implicado o abandono da base construída no Douro, dirigindo-se este grupo então de novo ao Atlântico, para penetrar no Ave, mais a norte ${ }^{11}$. Mas a sua acção predatória estendeu-se também ao sul do Douro, havendo dela registo também nas terras de Santa Maria, entre o Douro e o Vouga ${ }^{12}$.

Do exposto, depreende-se que, por essa época, se registava uma intensa actividade marítima nas costas do Norte de Portucale, com especial incidência nos rios Ave e Douro. Não seria possível que estes eventos se tivessem desenrolado autonomamente, sem que os gascos, de tal modo fortes que tinham conseguido ocupar um território vizinho do que era dominado pelas tropas muçulmanas, se tivessem tentado opor aos vikings, impedindo o estabelecimento

\footnotetext{
8 Publicado por Azevedo (1973).

9“[...] No mês de Julho da Era 1053 (1015 DC) os filhos e descendentes dos Normandos invadiram o Douro, devastando e cativando gente entre o rio Douro e o rio Ave durante nove meses. Raptaramme, a mim, Amarelo, três filhas, e fiquei pobre. Passaram depois os Normandos para vender todos os cativos e eu não tinha que Ihes dar para resgatar as minhas filhas Serili, Ermesenda e Faquilo [...]".

10 Sobre esta ocorrência, ver o recente Barroca \& Silva (2018).

11 A realização, por parte dos "Iordemanos", desta campanha por terra parece-nos de pôr de parte, já que implicaria a perda da eficácia que decorria do transporte naval que lhes era característico (cf. Barroca \& Silva, 2018).

12 Referimo-nos ao documento publicado nos PMH, DC 261, datado de 1026, que provavelmente se refere ainda à mesma campanha viking, embora sendo de redacção mais tardia. Sobre a interpretação deste documento, ver Barroca \& Amaral \& Marques (2018).
} 
de uma base militar de Inverno e a consequente predação de gentes e bens. A menos que os dois grupos invasores agissem coordenadamente ou, pelo menos, observando um acordo de não-agressão, uma vez que os objectivos de ambos eram distintos, mas paralelos. E os adversários, em alguma medida, podiam bem ser os $\operatorname{mesmos}^{13} \ldots$

\section{O xadrez político ibérico e a actividade naval}

É neste momento, porém, que se torna necessário olhar mais ao longe, observando o que se passava ao longo da costa portuguesa e galega. Na realidade, sabemos que o movimento de embarcações vikings era intenso desde o século IX, o que significa que as populações teriam já adquirido hábitos defensivos, nomeadamente afastando-se da costa e abandonando as actividades ligadas ao mar, como a pesca. Pelo que sabemos, os poderes militares situados a Norte havia muito que se mostravam incapazes de se opor a estas sucessivas incursões, tendo aliás sofrido períodos de intenso assédio ${ }^{14}$.

A sul, porém, as coisas passavam-se de um modo diferente, encontrando aí as armadas normandas forte resistência por parte das autoridades do Al Andalus que, através de frotas bem coordenadas a partir de Cádiz, os impediam de penetrar com facilidade no Mediterrâneo. Talvez esse facto explique a intensidade dos ataques destes corsários ao Norte da Península, quando era sabido que a maior cópia de riquezas se encontrava para sul. É bem possível, todavia, que os nórdicos tenham tentado um golpe de força quando Olafr Haraldsson, no ano de 1014, ensaia uma expedição marítima que, segundo as fontes historiográficas disponíveis ( $c f$. Historia Norwegiae, apud Stefánsson, 1908-1909), se deslocou até Espanha, mas acabou por refluir para norte, terminando aquele jovem guerreiro por aportar na Normandia francesa, onde o seu primo bispo... o baptiza, fazendo-o regressar à sua terra como primeiro rei cristão da Noruega - mais tarde "Santo Olavo". Muitos historiadores se debruçaram já sobre a santidade deste guerreiro que, segundo fontes poéticas, terá chegado ao estreito de Gibraltar, onde terá tido uma visão divina que o aconselhou a voltar para a sua terra, tornando-o seu primeiro rei cristão ${ }^{15}$. $\mathrm{Na}$ realidade, o que parece verosímil é que Olafr, perante a resistência oferecida pela frota andaluza, se tenha visto obrigado a regressar sem concretizar os seus propósitos predatórios, tendo então mudado de táctica e privilegiado o reforço do seu poder institucional na terra de onde era originário.

\footnotetext{
${ }^{13}$ Não é taxativo, no documento atrás citado, que os invasores fossem exclusivamente nórdicos, embora estivessem com eles aparentados...

${ }^{14}$ Toda esta matéria foi recentemente desenvolvida com detalhe por Pires (2018).

15 "It may be added, to complete the subject, that St. Olaf, in A.D. 1014, probably reached the coast of the Spanish peninsula, and some of the battles recorded in his Saga may have been fought there. The places cannot be identified, but it is stated that he was turned back by a dream, while waiting for a fair wind to take him to Niörvasund, the Straits of Gibraltar" (Stefánsson, 1908-1909).
} 


\section{JOSÉ CARLOS RIBEIRO MIRANDA}

Expedição à Península Ibérica de Olafr Haraldsson, rei da Noruega (Santo Olavo), em 1014
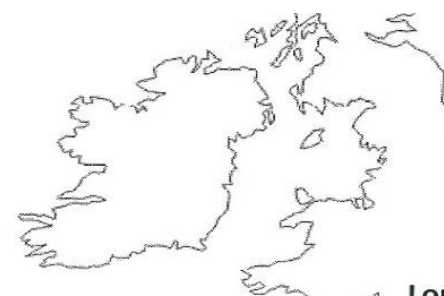

Gasconha/Vasconia
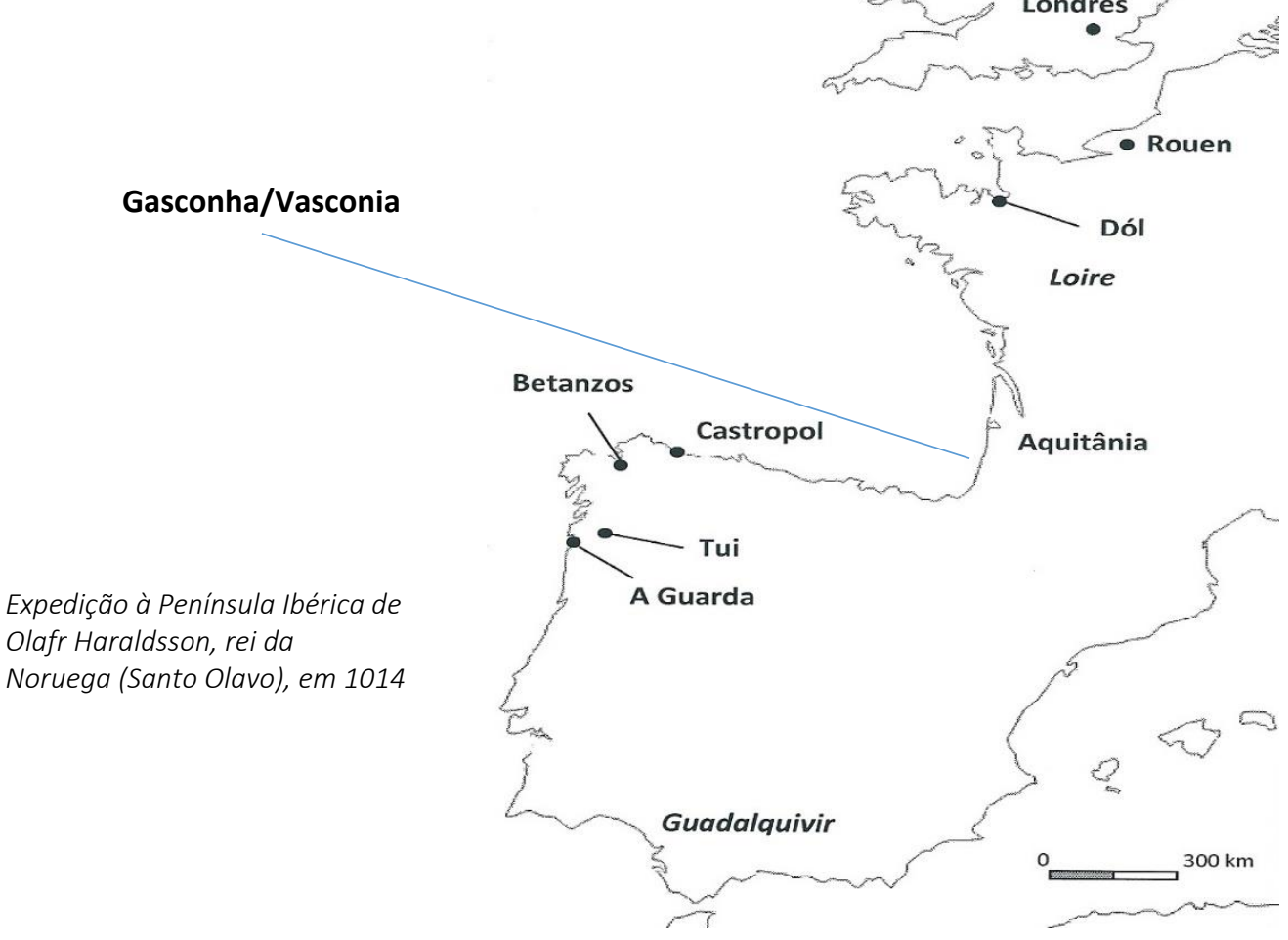

É certo que alguns autores alimentam sérias dúvidas sobre a presença de Olafr Haraldsson nos mares ibéricos, o que parece justificado dado as fontes que apontam nesse sentido serem muito tardias, mais de um século posteriores aos eventos em causa. Mas essas dúvidas não podem invalidar um facto incontroverso, que é a presença insistente de "lordemanos" e outros marinheiros com eles relacionados nareferida orla marítima nestes precisos anos de 1014 a 1016. Com rei da Noruega ou sem ele.

Ou seja, nesses anos, pouco após a retirada de Almansor, o mar português conhecia um tráfego muito intenso, comsucessivas expedições vindas do Norte a que se opunham, como podiam, as forças terrestres locais e também a frota muçulmana de Cadiz. Mas, apesar do domínio mouro sobre parte substancial da margem sul do rio Douro, o território português e galego estava já demasiado longe para que a oposição desta força naval constituísse elemento dissuasor dos invasores. Normandos dos clãs nórdicos mais importantes [...], normandos já instalados como colonizadores ao longo da costa francesa, gascos e eventualmente navarros que com estes fariam causa comum, afluem em vagas paralelas e aparentemente sem conflitos 
entre si, o que leva a ponderar se não seriam todos parte de uma mesma ofensiva, embora organizados em grupos diversos na composição e nos objectivos ${ }^{16}$.

\section{Os "Araldes" do Douro}

Há outros elementos nos livros de linhagens e na documentação disponível que podem levar a considerar viável esta possibilidade, nomeadamente a onomástica que lhes anda associada. Com efeito, é de novo o Livro Velho de Linhagens a informar que se implanta no Douro uma outra linhagem - no mesmo território de Baião onde, num primeiro momento, se instalara Monio lo Gasco -, cuja figura de proa é Gosendo Araldes. Não há que duvidar da sua existência histórica já que, afortunadamente, um documento da época, embora transcrito já muito tardiamente, declara que este se deslocou em 1029 à corte do futuro Fernando Magno em defesa de uma causa judicial na qual eram litigantes os monges de Suilhães e Garcia Moniz (de Ribadouro?):

[...] Alfonsum et Joanem, prebyteros, contra Garcea Monis, proinde ad junctissimus in Castella per manus Didaci Trutesendis et Menendo Dias et Gosendo Araldes, quae erat vicarius de rey Dono Fernandu et presentavit illos ante regem... [...] Era milesima sexagesima septima pridie Kalendas Jannarii $(1067=1029$, último dia de Dezembro)

Tem-se assumido que este documento ${ }^{17}$ está mal datado, provavelmente porque, no conhecimento histórico comum, Fernando Magno só é senhor de Castela em 1035, após a morte do pai, Sancho III de Navarra, que os anais desse reino e o Liber Regum declaram que foi "sennor tro en Portugal" ( $c f$. Miranda, 2009; Bautista, 2009), e que, após um muito longo reinado, reparte os territórios debaixo da sua soberania pelos dois filhos legítimos - Garcia e Fernando - e um ilegítimo - Ramiro. Mas essa objecção - se é que existe - esquece que o futuro rei Fernando Magno executava já actos de governo em Castela desde Julho de 1029, pouco depois da morte de seu tio, o conde Garcia Sanchez, e tendo sua mãe, Munia, herdado o condado $^{18}$. Que fosse ele a presidir a um tribunal onde Gosendo Araldes, "vicarium regis", intervém como um dos três "infanzones" portucalenses presentes, não é surpreendente, antes revela que a fidelidade deste senhor do Douro ao seu soberano navarro abrange também o

\footnotetext{
${ }^{16}$ Trataremos noutra altura o surgimento da comunidade de pescadores oriundos da Noruega junto à Póvoa do Varzim, na aldeia das Caxinas, cuja infausta particularidade é ser portadora, em escala muito elevada, de uma patologia genética denominada "paramiloidose". Adiantaremos, todavia, que nos parece provável que essa comunidade se tenha fixado em território portucalense na sequência do conjunto de acontecimentos a que nos temos vindo a referir.

$17 \mathrm{O}$ documento encontra-se publicado em Argote (1774: 438-440), estando igualmente presente no Censual da Sé do Porto (Anónimo, 1924). A primeira edição remete para o manuscrito com base no qual se realizou a segunda, ou apenas alude à sua existência. Em todos os testemunhos, a data indicada é a mesma: "Era 1067". Todavia, insatisfeita com tal datação, uma mão anónima irá reformulá-la no exemplar da edição do século XVIII a que temos acesso, passando a ser: "Era 1094/ano 1059". Desconhecemos em que se fundamenta tal datação que, no entanto, tem vindo a ser sido acolhida pelos historiadores que temos citado ao longo do presente trabalho.

18 Martínez Díez (2005: 150): "regnante gratia Dei, principe nostro domno Sanctio et prolis eius Fredinando comes". O documento está datado de 7 de Julho de 1029. Num contexto em que Sancho III é designado "princeps" e o seu filho "comes", não surpreende que ambos possam ser tratados como "reges" por alguém do exterior que assume uma condição de subordinação política e social.
} 


\section{JOSÉ CARLOS RIBEIRO MIRANDA}

filho deste ${ }^{19}$. Tais questões, que se revelam de uma extraordinária importância para a história portuguesa da primeira metade do século XI, deverão, naturalmente, merecer um estudo mais detido e aprofundado, envolvendo todas as vertentes do problema, tanto históricas como filológicas. Anote-se, todavia, que esta perspectiva é substancialmente diversa da adoptada pela historiografia portuguesa ( $c f$. Fernandes, 1960; Mattoso, 1985; Sottomayor-Pizarro, 1997, I), que pretende que os de Baião desta época continuam uma ocupação do território donde retiram o nome que remontaria a muitas gerações atrás. O que não se entende, nesse caso, é de que forma e por que via Dom Monio lo Gasco e seus acompanhantes teriam começado por se estabelecer nesse mesmo território de $\mathrm{B} a \mathrm{iã} \mathrm{O}^{20}$, quando já lá estariam os hipotéticos ascendentes de Gosendo Araldes. E ainda como teriam adquirido, por meados do século XI, uma tão grande supremacia social e territorial, bem visível no conjunto de instituições monásticas que fundaram em ambas as margens do Douro ( $c f$. Mattoso, 1995, I: 165 e seg.).

Seja como for, se Gosendo Araldes está já presente no território português na década de 20 desse século, isso é consistente com a referência feita no mencionado documento a um bispo Dom Sisnando, que o mesmo livro declara ter vindo com Dom Monio lo Gasco, estando ambos de facto sepultados em Vila Boa do Bispo ${ }^{21}$. O Livro de Linhagens do Conde Dom Pedro vai mesmo mais longe, declarando que uma outra personalidade com idêntico patronímico, que está na origem da linhagem dos Urgeses, teria pertencido ao mesmo grupo que em 1014 se apresenta no Douro: "Dom Cresconho Araldez veo de Gasconha com Moninho o Gasco, o Velho". Embora o Conde se apresse a dar a Gosendo Araldes uma filiação num tal Arvaldo22, cuja proveniência é totalmente desconhecida - a menos que fosse também um "gasco", para estar de acordo com a restante narrativa -, cremos que é de ponderar outra possibilidade para a explicação desse pseudo-patronímico atribuído aos membros fundadores dos de Baião e de Urgeses.

De facto, "Araldes" parece ser um genitivo patronímico de "Arald", ou "Harald", a designação de um dos mais importantes clãs vikings que sulcavam os mares atlânticos ${ }^{23}$, o que significa que quem ostentava tal nome não era obrigatoriamente filho de algum "Harald", mas podia apenas pertencer a esse clã. "Araldes" não será mais do que uma adaptação ibérica dessa designação genérica de grupo, transformada em genitivo patronímico segundo os hábitos onomáticos correntes nesta região. Como vimos atrás, Santo Olavo - "Olafr" -, é também ele um "Haraldsson". Se esta explicação se revelar viável, então duas das mais importantes linhagens do Douro - absolutamente icónicas da fundação futura de Portugal enquanto reino -, terão provavelmente ligação a um estrato social de origem normanda, ou andavam, pelo menos, muito ligadas a essa origem. Por outro lado, a sua vinda a partir da Gasconha deve ser

\footnotetext{
${ }^{19}$ Sobre o contexto político do território do centro da Península no século XI, ver Menéndez Pidal (1929); Lacarra (1972).

${ }^{20}$ A verosimilhança histórica da narrativa do Livro de Linhagens do Conde D. Pedro, nas suas grandes linhas cronológicas, sociais e políticas, é aceite por Mattoso (1995, I: 166).

${ }^{21}$ Cf. Investigação recente confirma a contemporaneidade de Monio Gasco e do Bispo Sesnando, tal como pretendem os livros de linhagens, e da filiação de Garcia Moniz - o fundador de Travanca - no procer gasco. É esta última personalidade contra a qual é movida a queixa por parte de dois monges de Suilhães, levada ao juízo do "rei" Fernando, sendo Gosendo Araldes vicarius deste último (cf. Barroca, 2000, I: 295).

22 "Arualdo" pode não ser mais do que um alógrafo de "Arald", tornado em "Araldo" pelas características da língua do ocidente ibérico.

${ }^{23}$ Segundo Hudson (2005), o outro clã dominante nas campanhas marítimas nórdicas é o dos "Olafsson".
} 
entendida no contexto da problemática das ligações entre os normandos e a Gasconha, num contexto em que a Normandia cristã estava instituída havia um século, e mesmo os piratas activos nessa altura no Atlântico possuíam um comandante que estava já muito próximo de vir a ser um rei cristão.

Com os dados disponíveis, cremos ser de avançar estas possibilidades, tendo presente que os indícios que apontam no sentido de as validar são múltiplos e provenientes de fontes diversas.

Sintetizando, nos anos de 1014 a 1016 o Douro situado em Portucale foi palco de uma intensa actividade que não deve ser reduzida à peculiaridade mais ou menos folclórica de uns quantos piratas que assolaram as costas. É bem provável que, num contexto de luta pelo poder tanto no mar como em terra, se tenham ora oposto, ora coincididotacticamente, contingentes navais normandos, muçulmanos e cristãos segundo alinhamentos que não é fácil discernir. Neste ponto da Península Ibérica, aproveitando um período de notável enfraquecimento militar e político do reino leonês, forças cristãs oriundas de territórios diversos - Navarra e Gasconha, sem dúvida - decidem assumir a iniciativa militar e colonizadora, no que se vêem coroadas de êxito, muito embora a memória desses tempos se encontre esbatida e sobreposta por outras memórias provavelmente mais inteligíveis para os vindouros. Deste período terá resultado um momento fulcral na recomposição dos grupos sociais e políticos dominantes no Douro interior, donde emergirá uma poderosa aristocracia - cujas linhagens mais relevantes serão os de Ribadouro e os de Baião - que redefiniu os rumos da região no seu todo, operação concluída mais tarde, quando Fernando Magno decide completar o plano do seu pai, Sancho III de Navarra, e juntar ao Alto-Douro toda a Beira até ao eixo Coimbra-Viseu-Seia, após, naturalmente, ter assegurado a fidelidade da cidadela fulcral de todo este território, que é indubitavelmente Lamego.

\section{BIBLIOGRAFIA:}

ANÓNIMO (Ed.). (1924). Censual do cabido da Sé do Porto. Porto: Imprensa Portuguesa.

ARGOTE, Jeronymo (1774). Memorias para a Historia Ecclesiastica do Arcebispado de Braga..., T. III. Lisboa: Regia Oficina Sylviana.

AZEVEDO, Rui Pinto de (1973). A expedição de Almançor a Santiago de Compostela em 997, e a de piratas normandos à Galiza em 1015-16. Revista Portuguesa de História, Tomo XIV, 7393.

BARROCA, Mário (2000). Epigrafia Medieval Portuguesa (862-1422). 4 voll. Lisboa: Fundação Calouste Gulbenkian.

BARROCA, Mário \& SILVA, Armando (Eds.). (2018). Mil anos da incursão normanda ao castelo de Vermoim, organizado por Mário Jorge BARROCA \& Armando Coelho Ferreira da SILVA. Porto: CITCEM.

BARROCA, Mário \& AMARAL, Luís \& MARQUES, André (2018). As incursões Vikings no norte de Portugal. In Mário BARROCA \& Armando SILVA (eds). Mil anos da incursão normanda ao castelo de Vermoim (pp. 143-184). Porto: CITCEM.

BAUTISTA, Francisco (2009). Breve historiografía: Listas regias y Anales en la Península Ibérica. Siglos VII a XII. Talla dixit, 4, 113-190.

CHRISTYS, Ann (2015). Vikings in the South: Voyages to Iberia and the Mediterranean. London/New York: Bloombury.

COLLINS, Roger (1990). The Basques. London: Blackwell Publishing. 


\section{JOSÉ CARLOS RIBEIRO MIRANDA}

DUARTE, Luís Miguel (2003). A Marinha de Guerra Portuguesa. In Manuel THEMUDO BARATA \& Nuno Severiano TEIXEIRA (dir.), Nova História Militar de Portugal, I (pp. 290 e seg.). Lisboa: Círculo de Leitores.

ERKOREKA, Anton (2004). Los Vikingos en Vasconia. In Los vikingos en la Península Ibérica (pp. 9-40). Barcelona: Fundación Reina Isabel de Dinamarca.

FERNANDES, A. de Almeida (1960). Aç̧ão das Linhagens no Repovoamento e na Fundação da Nacionalidade (Sep. de Douro Litoral, IXa Série, vol. III).

FERREIRA, Manuel dos Santos da Cerveira Pinto (2004). O Douro no Garb Al-Ândalus: a Região de Lamego durante a presença árabe. (Dissertação de Mestrado). Braga: Universidade do Minho.

HUDSON, Benjamin (2005). Viking Pirates and Christian Princes: Dynasty, Religion, and Empire in the North Atlantic. Oxford: Oxford University Press.

LACARRA, José María (1972). Historia politica del reino de Navarra desde sus orígines hasta su incorporación a Castilla. Pamplona: Editorial Aranzadi.

MARTÍNEZ DÍEZ, Gonzalo (2005). El Condado de Castilla (711-1038): la bistoria frente a la leyenda. 2 voll. Valladolid: Junta de Castilla y León.

MATTOSO, José (Ed.). (1980). Portugaliae Monumenta Historica. Nova Série, voll. I \& II. Livro de Linbagens do Conde D. Pedro. Lisboa: Academia de Ciências de Lisboa.

MATTOSO, José (1995). Identificaşão de um País. Ensaio sobre as origens de Portugal (10961325). 2 voll. Lisboa: Estampa.

MATTOSO, José (2001). Infanções, Cavaleiros e Ricos-Homens. In Obras Completas (pp. 17-179). Lisboa: Círculo de Leitores.

MATTOSO, José \& PIEL, Joseph (Eds.). (1980). Portugaliae Monumenta Historica. Nova Série. Vol. I. Livros Velhos de Linhagens (pp. 21-60). Lisboa: Academia de Ciências de Lisboa.

MENÉNDEZ PIDAL, Ramón (1929). La España del Cid. Madrid: Editorial Plutarco.

MIRANDA, José Carlos Ribeiro (2009). A introdução à versão galego-portuguesa da Crónica de Castela (A2a): Fontes e Estratégias. In Seminário Medieval 2007-2008 (pp. 61-97). Porto: Estratégias Criativas.

MIRANDA, José Carlos Ribeiro (2016). Os trovadores e o rapto de Elvira Anes da Maia. Porto: Estratégias Criativas.

MONLEZUN, Jean-Justin (1846). Histoire de la Gascogne depuis les temps les plus reculés jusqu'à nos jours. Auch: J. A. Portes.

PÉREZ DE URBEL, Justo (1954). La división del reino por Sancho el Mayor. Hispania: Revista española de historia, 54, 3-26. Madrid: CSIC.

PIRES, Hélio (2018). Os Vikings em Portugal e na Galiza. As incursões Nórdicas Medievais no Ocidente Ibérico ( $3^{\mathrm{a}}$ ed.). Lisboa: Zéfiro, Edições e Actividades Culturais, Unipessoal Lda.

SÁNCHEZ PARDO, José Carlos (2010). Los ataques vikingos y su influencia en la Galicia de los siglos IX-XI. Anuario brigantino, 33, 57-86.

SOTTOMAYOR-PIZARRO, José Augusto de (1997). Linhagens Medievais Portuguesas. Genealogias e Estratégias (1279-1325). 2 voll. Porto: Universidade Moderna.

STEFÁNSSON, Jón (1908-1909). The Vikings in Spain. From Arabic (Moorish) and Spanish Sources. In Saga-Book of the Viking Club. Vol. VI. Proceedings (pp. 31-47). London: Viking Club - London King's College. 